\title{
Employment trajectories and later employment outcomes for mothers in the British Household Panel Survey: An analysis by skill level
}

Kitty Stewart

\section{Contents}

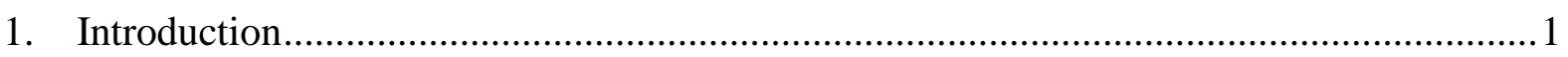

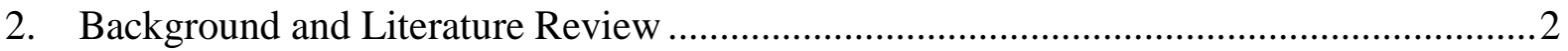

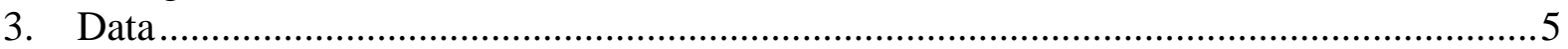

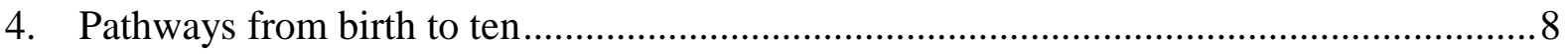

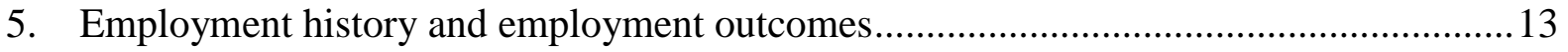

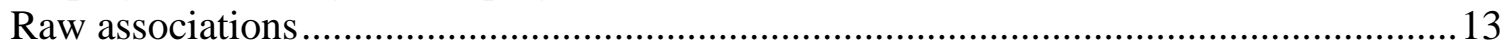

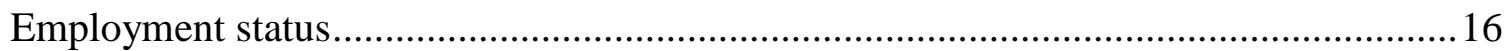

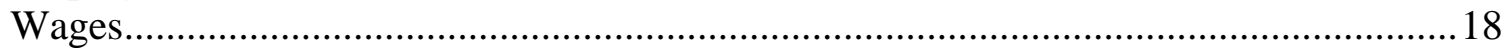

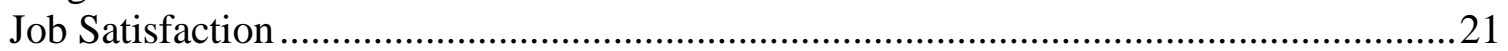

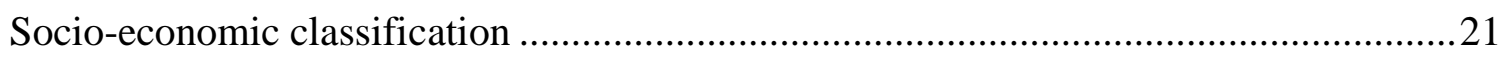

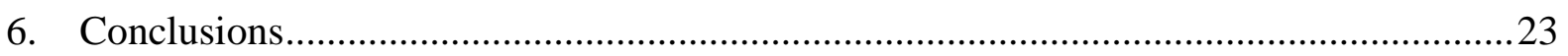

CASE/144

May 2011
Centre for Analysis of Social Exclusion

London School of Economics

Houghton Street

London WC2A $2 \mathrm{AE}$

CASE enquiries - tel: 02079556679 


\section{Centre for Analysis of Social Exclusion}

The Centre for the Analysis of Social Exclusion (CASE) is a multi-disciplinary research centre based at the London School of Economics and Political Science (LSE), within the Suntory and Toyota International Centres for Economics and Related Disciplines (STICERD). Our focus is on exploration of different dimensions of social disadvantage, particularly from longitudinal and neighbourhood perspectives, and examination of the impact of public policy.

In addition to our discussion paper series (CASEpapers), we produce occasional summaries of our research in CASEbriefs, and reports from various conferences and activities in CASEreports. All these publications are available to download free from our website. Limited printed copies are available on request.

For further information on the work of the Centre, please contact the Centre Manager, Jane Dickson, on:

Telephone: $\quad$ UK+20 79556679

Fax: $\quad$ UK+207955 6951

Email: $\quad$ j.dickson@1se.ac.uk

Web site: http://sticerd.lse.ac.uk/case

(c) Kitty Stewart

All rights reserved. Short sections of text, not to exceed two paragraphs, may be quoted without explicit permission provided that full credit, including (C) notice, is given to the source. 


\title{
Editorial Notes and Acknowledgements
}

Kitty Stewart is a Lecturer in the Department of Social Policy at the London School of Economics, and a CASE Associate. The author is very grateful to the Nuffield Foundation which has funded this research. She also thanks Francesca Bastagli for useful discussions while working on this paper, Abigail McKnight for very helpful comments on an earlier draft and Jane Dickson for preparing the text.

\begin{abstract}
Maternal employment formed a central plank in the former Labour Government's strategy to reduce child poverty. Even where potential jobs were low-skilled and lowpaid, policy was explicitly work (rather than training) first, and lone parents in particular were given direct and indirect financial subsidies to enter employment of any kind. The explicit assumption was that a low-paid job would be a stepping-stone to better things. From 2008 a little more stick was introduced to what had been a largely carrot-based approach to encouraging employment, a shift that has continued under the Conservative-Liberal Democrat Coalition Government in power from May 2010.
\end{abstract}

However, there is little evidence in practice that a low-paid job when one's child is young is a reliable route to improved future prospects. This paper uses the British Household Panel Survey to explore this issue further. It examines the employment trajectories of 929 women for the ten years after the birth of their youngest child, asking two main questions. Do mothers tend to remain in employment once they have taken a job? And do wages and other employment outcomes further down the line (when their youngest child is ten) reflect the employment pathway taken? In both cases the paper focuses in particular on differences between women with higher and lower levels of qualifications.

The paper finds mothers following a variety of employment pathways, with instability much more common than steady work trajectories. One in three mothers moves in and out of work over the decade after the birth of their youngest child, and this is true for both lower-skilled and higher-skilled mothers. Stable work histories do appear to carry benefits in terms of wages when the youngest reaches ten, but the benefits are substantially higher for women with higher levels of qualifications, as might be predicted by human capital theory. More highly qualified women who moved in and out of work over the decade had an hourly wage at ten which was 33\% lower than similar women with a stable work history; for women with few or no qualifications the corresponding figure was $14 \%$. Levels of occupational progression as measured by change in NS-SEC status over the decade were encouraging, but for both higher and lower skilled women job satisfaction when the youngest is ten appears unrelated to the pathway taken.

JEL Classification: J22, J24, J31

Keywords: maternal employment, employment trajectories, wage growth Corresponding author: Kitty Stewart (‥j.stewart@1se.ac.uk) 


\section{Introduction}

Maternal employment formed a key part of the former Labour Government's strategy to reduce child poverty. Even where potential jobs were low-skilled and low-paid, policy was explicitly work (rather than training) first, with an approach best summed up in a 1999 Treasury document: "Getting a job, keeping a job and having the chance to progress up the earnings distribution out of low-paid work are the key to improving life chances" HM Treasury (1999). Parents - particularly lone parents and first earners in couples - were given both direct and indirect financial subsidies to enter employment of any kind, through Child Tax Credits and support for childcare. While much more generous maternity leave and a 'Baby Tax Credit' made a year at home more viable for many, the assumption was that after this mothers should be returning to work. From 2008 a little more stick was introduced to this largely carrot-based approach to encouraging employment, with compulsory work-focused interviews introduced for lone parents of children aged three and over.

If a low-paid job is a good route to better employment prospects in the future, there is a strong case that heavy subsidy of low-paid work is a justifiable government strategy. First, it is a sensible investment for the Treasury, which should see a pay-off in higher future tax receipts. Second, an argument can be made that it is part of the role of government to enable and facilitate parents to do what is best for themselves and their children in the long-run.

But is there evidence that getting a low-paid job when one's child is young is a reliable route to improved future prospects? There is certainly considerable research evidence about the negative impact time out of the labour market has on women's wages and employment trajectories. For instance Waldfogel (1998) showed that women with job-protected maternity leave in the US and Britain returned to work sooner after childbirth, and that this reduced the 'family penalty', itself an important part of the gender pay gap. However, most of the research studies into family and gender pay gaps do not distinguish between women with different levels of qualifications, even though lost years of experience may be expected to matter more for women with higher skills. In assuming that time out will have a negative impact on wages and employment status for all women, regardless of skill level, policy discussion may be reflecting the average effect identified in the research findings.

At the same time, a separate literature on progression in employment for low skilled workers in general has found generally disappointing results: e.g. Stewart and Swaffield (1998) find limited mobility out of low pay in Britain, with the probability of moving out considerably lower for women than for men. Work focusing specifically on lone parents has pointed to the existence of "low pay-no pay" cycles, with lone parents moving into paid work at a rate similar to that of other nonemployed people, but leaving again at twice the rate (Evans et al. (2004)). Stewart (2009) also finds both employment instability and very limited progression out of low pay for a cohort of British lone parents. 
If mothers with low skills do not in fact tend to progress out of low paid jobs and onto better things, in the longer run we may see little difference between the employment status and wages of women who returned to work when their children were of preschool age and those who returned later. This would challenge some of the key assumptions on which policy in this area is currently based. Subsidising low paid work and childcare may still make sense - because of the benefits of childcare, the impact of higher contemporary income, or the importance of working role models for children - but not because of the long-term impact on women's future pay and prospects.

This paper seeks to further our knowledge in this area by examining maternal employment trajectories across a decade using data from the UK's longest running household panel, the British Household Panel Survey (BHPS). By creating a pseudopanel it identifies 929 women whose trajectory we can follow for ten years after the birth of their youngest child. Using these trajectories the paper aims to answer two questions. First, how far do mothers' employment patterns conform to what might be thought of as conventional pathways - a unidirectional movement from full-time care to full-time work, perhaps via a stepping stone of part-time work? As noted above, we know that lone parents display considerable short-term employment instability, but we do not know how differently partnered women's trajectories look, nor whether higher skilled women display much greater stability than those with fewer skills. We also do not know very much about how short-term transitions translate into a broader picture of employment trajectories over a longer time period.

Second, the paper asks how important early decisions are for later employment outcomes. Specifically, it looks at whether employment status when a youngest child is two or three helps predict employment outcomes as the child reaches the end of primary school. Clearly the answer here will be linked to the answer to the first question - more instability in employment pathways suggests a lower importance of an early return - but the extent of wage and employment progression for those mothers who do remain consistently in work will also be important. Four main employment outcomes are considered - being in work; the hourly wage; occupational status; and job satisfaction. Again, the paper is particularly interested in differences between women who have high educational attainment at the time of birth and those with lower or no qualifications.

\section{Background and Literature Review}

There is an extensive literature which examines the long-term impact that motherhood has on wages and employment status (see for example Waldfogel (1997) and Budig and England (2001) on the US; Waldfogel (1995) and Joshi et al. (1998) on the UK; Datta Gupta and Smith (2002) on Denmark; and comparative studies by Harkness and Waldfogel (2003) and Sigle-Rushton and Waldfogel (2007)). All but the Danish study identify a large long-term cost to motherhood in terms of foregone earnings - a 'family gap' between the wages of mothers and non-mothers, which in turn is a key 
driver of the gender pay gap. The comparative studies point to a particularly large family gap in the UK (Harkness and Waldfogel (2003)), and in the UK along with the Netherlands and Germany (Sigle-Rushton and Waldfogel (2007)).

Most of these studies seek to identify the driving factors behind the family gap, asking how far lower wages can be explained by reduced labour market experience as the result of time spent at home with children, and how far by other factors, including the switch to lower status but more family-friendly jobs, a switch to part-time work (which is often lower paid), lower productivity at work as a result of family responsibilities, and employer discrimination. While differing on the size of the role attributable to particular factors, all find the lost years of experience to be a crucial component.

The clear policy implication is that one way to decrease the 'family gap' (and with it the gender pay gap) is to minimise the length of employment breaks and get mothers back into the labour market quickly. Further studies support this idea more directly. Jacobsen and Levin (1995) suggest that breaks in employment at childbirth have longlasting effects on women's pay; while Waldfogel (1998) and Joshi et al. (1998) find that women who maintain employment continuity over childbirth have higher pay than those who do not. The UK strategy, which provides job-protected and part-paid maternity cover in the first year, followed by employment and childcare subsidies thereafter, thus appears to make considerable sense, both for gender equity and for economic performance.

However, few of the studies cited above attempt to distinguish between women by skill level. They assume a uniform relationship between experience and pay, estimating the average penalty across all working mothers, even though the value of experience may be expected to be lower in jobs that require fewer skills. It is more than plausible that experience as a teacher, doctor or astronaut results in the accumulation of more human capital than experience as a cleaner or factory machinist, with lost years in the former professions therefore likely to be associated with a greater wage penalty. To put it more formally, experience-earnings profiles may not be parallel for workers with different skill levels, and in this case it will be misleading to apply conclusions based on average returns to experience to any particular group.

Some recent studies do explore whether the family gap is different for women with different levels of qualifications. Perhaps surprisingly, this research has tended to find a reduced gap for those with higher skills, with higher education acting as what Todd (2001) calls a "shock absorber", insuring women against the earnings penalties associated with having children (see for example Budig and England (2001; Todd (2001); Anderson et al. (2003); Amuedo-Dorantes and Kimmel (2005)). Only Ellwood et al. (2009) identify a much higher cost to motherhood for high skilled than low skilled women. However, the focus in all these studies is on differences in the part of the gap which is not explained by experience (i.e. the part that may be due to work effort or discrimination); experience is included as a single control variable, with a 
single coefficient for women of all skill levels. ${ }^{1}$ This is a different question to the one at issue in this paper, which is about whether time out of the labour market is likely to have less impact on wages and other employment outcomes for women with fewer qualifications.

The wider literature on returns to experience for workers with different skill levels suggests that a lesser impact is likely. Using cross-sectional data for the US, Murphy and Welch (1992) and Lemieux (2003) find similar returns to experience for high and low skilled workers during the 1980s, with less educated workers experiencing a steepening of the earnings profile in the second part of the decade. But Card and DiNardo (2002) find that in the 1990s, earnings profiles flattened for less-educated workers, and steepened for more highly educated women, resulting in a substantially flatter profile for women with less than 12 years of education compared to women with 16. Using longitudinal data, Heckman et al. (1998) finds higher wage growth for more educated workers, but the differences are quantitatively small. Gladden and Taber (2000) find working high school dropouts have somewhat steeper profiles than workers with a high school degree. Using German longitudinal data, Dustmann and Meghir (2005) find positive returns to experience for skilled workers, and small and insignificant returns to unskilled workers after two years, but they do identify substantial returns to firm tenure. Connolly and Gottschalk (2006) find that both within-job and between-job wage growth are higher for more educated workers, for both males and females. They argue that the apparent wage growth of lower-skilled workers found in earlier cross-sectional regressions largely reflects improved job match rather than returns to tenure or experience.

Another set of literature which examines wage growth for low skilled workers or previous welfare recipients (without the comparison group of higher skilled workers) also raises questions about likely gains to experience in the medium-term. Burtless (1995) finds that former welfare recipients in the US experience less than a one percent per year growth in wages over a ten year period. Gladden and Taber (2000) find a small return to experience among low-skilled workers; while Connolly et al. (2003) find substantial upward mobility even from "dead-end" jobs, but only for a minority of workers. Card et al. (1999) finds growth of between 1.6-2.6 percent per year for long term welfare recipients in Canada. In the UK, Stewart and Swaffield (1998) find limited mobility out of low pay using the BHPS, with considerably lower mobility for women. Using the New Earnings Survey, McKnight (2000) similarly finds more upward mobility in earnings for men than women. Mobility increased for women and declined for men in the two decades to 1997, but a considerable degree of persistence in low pay remained. Among lone parents in particular, Harkness (2006) finds that around half of those in the Families and Children Study who ever worked between 1999 and 2003 were permanently low-paid (their earnings never rose beyond two-thirds of the male median wage). Using the British Lone Parent Cohort, Stewart (2009) also finds very limited wage progression over a longer period (six to twelve

Strictly speaking, a double control variable and a double coefficient, as a quadratic term for experience is usually included. 
years), with more women moving into than out of low pay during the observation period.

Finally, another relevant group of studies explore stability in employment for lowskilled workers. The discussion above largely concentrates on how far those who remain in employment progress up the wage distribution. But we know that churning or cycling in and out of jobs is much more likely in the low-skilled labour market: that is, we cannot assume that women moving into work are likely to stay there thereafter. Stewart and Swaffield (1999) and McKnight (2000) both find that lower-paid workers in general have a less stable pattern of employment than higher-paid workers. Among lone parents in particular, research by Evans et al. (2004) found a similar rate of movement into paid work as for other non-employed people, but a rate of exit which was twice as high. Stewart (2009) found considerable movement in and out of work for lone parents in the six to ten years after the birth of a youngest child.

This paper, part of the same larger research project as Stewart (2009), extends that work using a different dataset, the BHPS. Its overriding question is whether moving into work soon after the birth of a child matters to later employment outcomes. To do this, it asks two sub-questions. Do mothers on the whole remain in employment once they have taken a job (and how does this differ by skill level)? And do wages and other employment outcomes further down the line (when their youngest child is ten) reflect the employment pathway taken - and how does this differ by skill level? We start by exploring the BHPS and its advantages to the study.

\section{Data}

The BHPS is a longitudinal dataset which contains information from a sample of households interviewed annually since 1991, with 17 waves available at the time of analysis (1991-2007). All female respondents with a youngest child aged ten in any particular wave were included in the analysis for this paper, as long as information was also available on their employment status in each year since birth. As the BHPS collected full fertility and employment histories in the third year of the survey, this meant women could be included even when the youngest child reached ten in an early wave, but it did exclude some of those who joined the panel later (for example by marrying an original panel member, or through various booster samples). The total sample was 929 women spread fairly evenly across the 17 waves of the BHPS (between 45 and 69 observations in each wave, or $4.8 \%-7.4 \%$ of the total 929). All of these had observations for every year (in a few cases - fewer than 30 - some interviews had been missed but we could complete the information using the job history from the next interview that did take place). We focus on youngest children to ensure that we can follow women for a decade in which their employment histories are uninterrupted by later births.

The BHPS has a number of advantages for this analysis. First, the ability to construct past employment histories in this way allows us to compare women's outcomes at the 
same life stage; we have chosen the point ten years after the birth of the youngest child. Second, the data allow us to look at differences in the experiences of mothers with lower and higher qualifications. In contrast, earlier work using the British Lone Parent Cohort was restricted to a more homogenous sample (Stewart (2009)). We also have much better information on employment history prior to the birth than was available in the BLPC. The disadvantage is somewhat smaller numbers of lower skilled women, and a sample size for lone parents which is too small for separate analysis.

Table 1 presents some descriptive statistics for the mothers at the point at which their youngest child is ten years old. Because of the way the panel is constructed, this is the point at which we have most information for the women - often we are building the earlier trajectory from the information in job and fertility histories. Of course, for some women this point will have been as early as 1991 and for others as late as 2007, meaning that women are facing different employment and wage conditions at what looks like the same point. To control for this as best we can we adjust all wage data to September 2007 prices using the Average Earnings Index, and we include a set of year dummies in all the regression analysis later in the paper.

The focus on pathways after the birth of the youngest child raises additional issues, as these pathways will clearly have been affected by employment and fertility histories prior to that birth. However, if we do not restrict the sample in this way the analysis will be complicated by exits from the workforce on the birth of subsequent children. To control for prior history we include variables in the regressions for the number of children and the years of potential and actual labour market experience.

The pathways are measured as annual snapshots: we examine the employment status of the mother at the time of each annual BHPS interview, beginning with the interview which takes place in the year after the child's birth. Where pathways are constructed for years prior to 1991 using the employment histories, job status is taken at a fixed point in each year, October 1, chosen because three-quarters of the 1991 interviews took place in September or October. ${ }^{2}$ This approach is taken because it considerably simplifies analysis, but it has two limitations. First, it groups children together by age in years not months: a baby aged nought could be anywhere between one month and eleven months old. This means we need to be very careful about interpreting data on what mothers are doing in the first year in particular. Given that our emphasis here is on longer term trends this does not seem too problematic. Second, the snapshot approach will not capture the full story for all women - a move in and out of work between snapshots will go unobserved, as will a break in employment which does not coincide with the interview date. Other research has suggested that year on year observations provide as good a view of employment

97\% of the 1991 BHPS interviews took place between September and November of that year. On average between 1991 and $200787 \%$ of all the interviews took place in this three-month period of the year, although between 1999 and 2002 the percentage drops sharply, with up to one third of interviews taking place during other months. 
patterns as examining inter-year data (Evans et al. 2004), so we hope that not too much information is lost in this way, but in interpreting our results we need to be mindful that the picture presented represents an upper bound on stability.

Finally we should clarify that skill levels are measured in the paper by the highest level of qualifications held. Unless otherwise indicated, skill levels are measured as soon as possible after the youngest child's birth. (If the youngest was born before the first interview in 1991 skill levels are measured in 1991). Mothers with higher education, A-levels or vocational education are classified as "high-skilled", while those with O-levels/GCSEs or no qualifications are classified as "low-skilled".

Table 1: Descriptive statistics: Mothers when their youngest child is ten

\begin{tabular}{|c|c|c|c|c|}
\hline & Median & Mean & SD & $\mathbf{N}$ \\
\hline Age of mother & 40 & 40 & 5.2 & 929 \\
\hline Number of children & 2 & 1.8 & 0.7 & 929 \\
\hline Hourly pay (September 07 prices) & $£ 7.73$ & $£ 9.37$ & $£ 5.25$ & 571 \\
\hline \multicolumn{4}{|c|}{ Percentage } & $\mathbf{N}$ \\
\hline \multicolumn{4}{|l|}{ Top qualification: } & 911 \\
\hline Degree & $14.8 \%$ & & & \\
\hline A level/Vocational & $41.0 \%$ & & & \\
\hline O level/GCSE & $25.8 \%$ & & & \\
\hline No qualifications & $18.3 \%$ & & & \\
\hline \multicolumn{4}{|l|}{ Tenure } & 929 \\
\hline Owner-occupier & \multicolumn{3}{|l|}{$75.5 \%$} & \\
\hline LA or Housing Association renter & \multicolumn{3}{|l|}{$18.1 \%$} & \\
\hline Private or employer renter & \multicolumn{3}{|l|}{$4.5 \%$} & \\
\hline Lone Parent & \multicolumn{3}{|l|}{$23.1 \%$} & 929 \\
\hline Employed in paid work & \multicolumn{3}{|l|}{$74.6 \%$} & 929 \\
\hline Employed full-time & \multicolumn{3}{|l|}{$38.0 \%$} & 915 \\
\hline Employed part-time (<30hours) & \multicolumn{3}{|l|}{$36.2 \%$} & 915 \\
\hline Manager/supervisor & \multicolumn{3}{|l|}{$28.6 \%$} & 643 \\
\hline \multicolumn{4}{|c|}{ Socio-economic classification (NSSEC), employed mothers } & 706 \\
\hline Higher professional/managerial & \multicolumn{3}{|c|}{$4.3 \%$} & \\
\hline Lower professional/managerial & \multicolumn{3}{|l|}{$29.9 \%$} & \\
\hline Intermediate & \multicolumn{3}{|l|}{$19.6 \%$} & \\
\hline Employers in small organisations & \multicolumn{3}{|l|}{$7.5 \%$} & \\
\hline Lower supervisory/lower technical & \multicolumn{3}{|l|}{$5.0 \%$} & \\
\hline Semi-routine & \multicolumn{3}{|l|}{$20.0 \%$} & \\
\hline Routine & \multicolumn{3}{|l|}{13.9} & \\
\hline
\end{tabular}




\section{Pathways from birth to ten}

Figure 1 shows the changing share of women working full-time, part-time (below 30 hours) and remaining at home in the ten years after the birth of the youngest child. The share of women not in paid work declines sharply in the first two years and then gradually over the period, with another steep fall at the time the child starts primary school. The share in full-time work rises steadily, while the share working part-time rises to age five and then stabilises, starting to decline when the child reaches eight, seemingly as mothers switch from part-time to full-time work. However, these are aggregate figures for the sample as a whole and tell us nothing about movement in and out of work for individual women.

Figure 1: Mother's employment status by age of youngest child

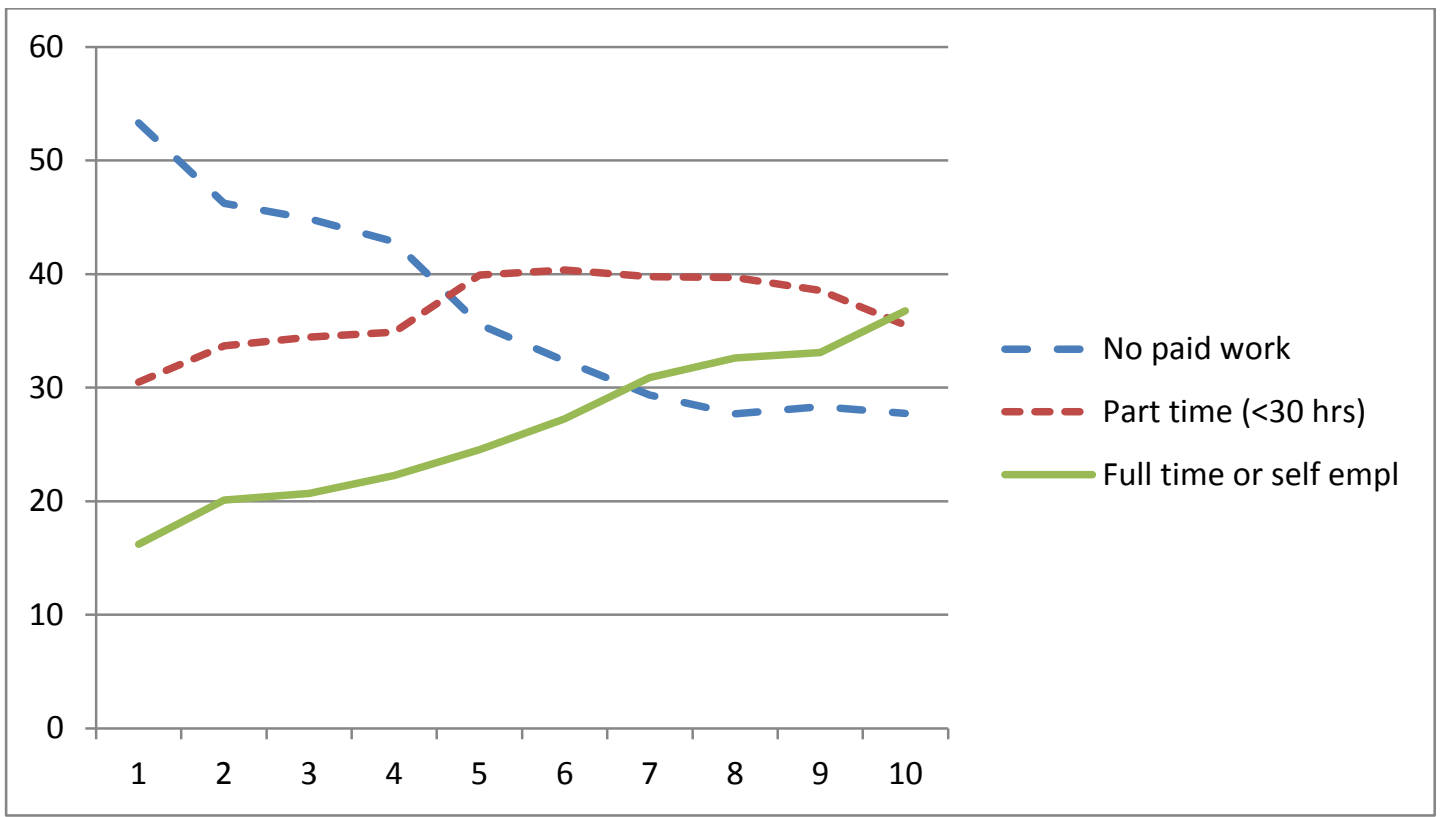

Source: Author's calculations from BHPS

Notes: Cross-sectional weights used (xewg). Unweighted N between 905 and 1553 .

Table 2 shows the breakdown of pathways followed by individual women over the decade. We find that $16 \%$ are observed in work in every interview from the first observation after birth, and a further $37 \%$ move into work at some point during the period and are observed working at each interview thereafter. Only $11 \%$ of the sample are observed at home in all eleven observations. What is perhaps really interesting here is the one-third of women who follow "in-out" pathways, by which we mean they are observed making at least two transitions - for example, entering work and then leaving again. Of this group, about half were observed mostly in work (at least six times out of eleven) and half mostly at home. Remember that for all women this is the trajectory after the birth of the youngest child, so is not explained by later births, and as such seems quite a high level of instability. Figure 2 shows - as expected - far higher instability for the mothers than for comparison groups of men and women without children during the decade of their 30 s. 
Table 2: Employment trajectories over the ten years after the birth of a youngest child

\begin{tabular}{lccc}
\hline & $\begin{array}{c}\text { Number } \\
\text { (unweighted) }\end{array}$ & $\begin{array}{c}\text { Percentage } \\
\text { (unweighted) }\end{array}$ & $\begin{array}{c}\text { Percentage } \\
\text { (weighted) }\end{array}$ \\
\hline Stable in work & $\mathbf{1 6 0}$ & $\mathbf{1 7}$ & $\mathbf{1 6}$ \\
Work enter & $\mathbf{3 4 7}$ & $\mathbf{3 7}$ & $\mathbf{3 7}$ \\
$\quad 182$ & 20 & 19 \\
By age 3 & 73 & 8 & 9 \\
3-5 & 92 & 10 & 9 \\
6+ & $\mathbf{2 9 5}$ & $\mathbf{3 2}$ & $\mathbf{3 4}$ \\
Work in out & 61 & 7 & 8 \\
1 or 2 periods in & 74 & 8 & 8 \\
3-5 periods in & 100 & 11 & 12 \\
6-8 periods in & 60 & 6 & 6 \\
1-2 periods out & $\mathbf{1 4}$ & $\mathbf{2}$ & $\mathbf{2}$ \\
Work exit & $\mathbf{1 1 3}$ & $\mathbf{1 2}$ & $\mathbf{1 1}$ \\
Stable out of work & & & 100 \\
Total & 929 & 100 & \\
\hline
\end{tabular}

Source: Author's calculations from BHPS

Notes: Longitudinal respondent weights were applied for the figures in the final column. "By age 3" means observed in work at the interview after the child's second birthday; "3-5" means not in work at this point, but has entered work by the interview after the child's fifth birthday; " $6+$ " means has entered at or after the interview after the child's sixth birthday.

Because the analysis is based on a single annual snap-shot, the $34 \%$ figure is almost certainly an underestimate of the true extent of employment instability; it misses any transitions which take place during the year. It also does not show movement between jobs. To capture some of this movement while retaining the simplicity of the annual snapshot approach, Table 3 breaks the main trajectory groups down according to parttime/full-time status. This table shows transitions in and out of full-time work within some of the more stable categories. For example, among the $16 \%$ who are in steady employment throughout, more than a third are seen moving in and out of full-time work over the decade, or leaving full-time work for part-time (the 'mix' category in the table). 
Figure 2: Employment trajectories over a decade: mothers, women without children and men

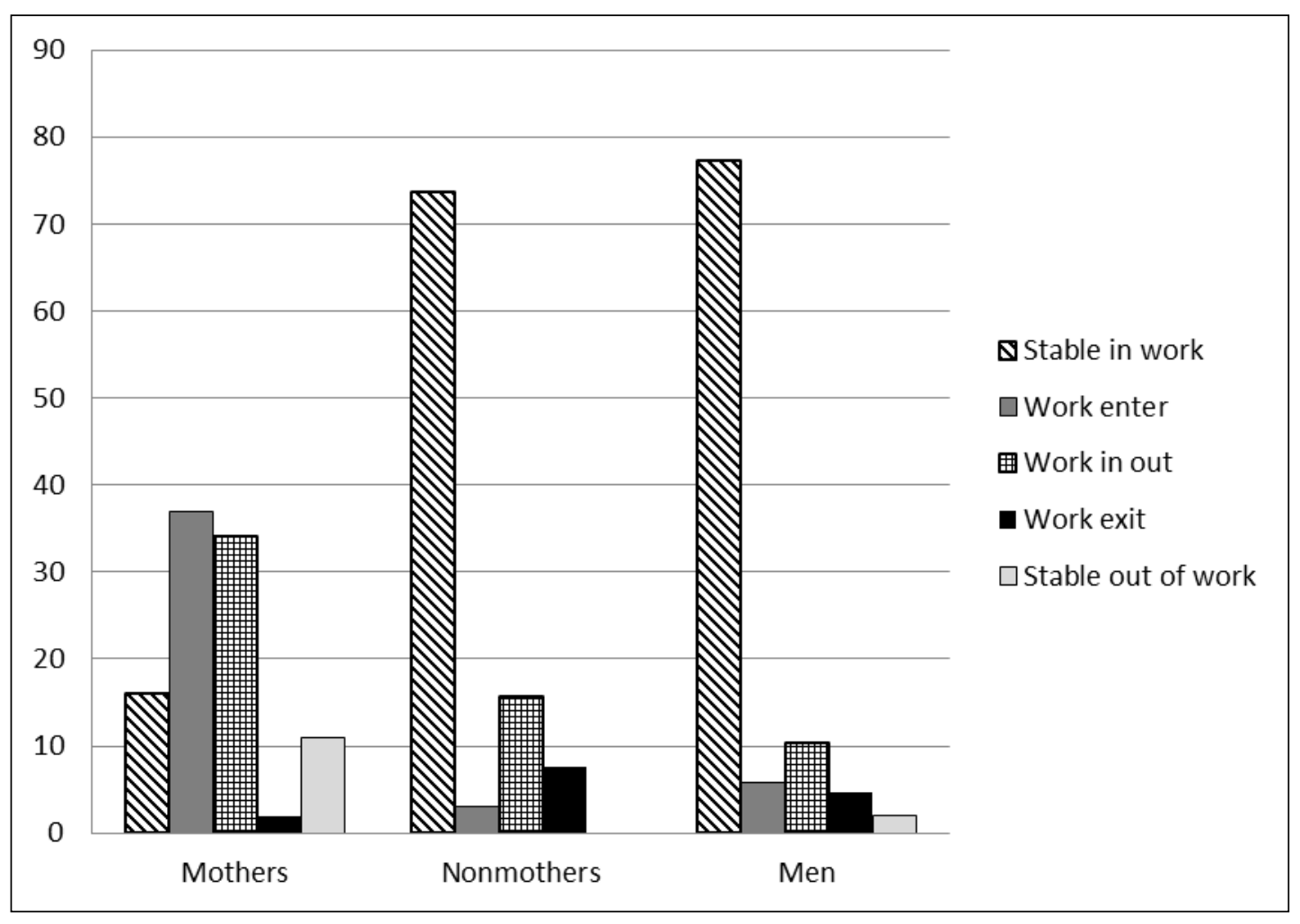

Note: The comparison samples include all women without children and all men whose employment trajectories from age 30 to age 40 were fully covered during the 1991-2007 rounds, with no missing data. This included 505 men and 95 women. The 30-40 decade was chosen because 30 is the median age of the mothers at the first observation after the youngest child is born. Data were weighted using longitudinal weights, as in Table 1. 
Table 3: Employment trajectories with part-time/full-time breakdown

\begin{tabular}{lrrr}
\hline & $\begin{array}{c}\text { Number } \\
\text { (unweighted) }\end{array}$ & $\begin{array}{c}\text { Percentage } \\
\text { (unweighted) }\end{array}$ & $\begin{array}{c}\text { Percentage } \\
\text { (weighted) }\end{array}$ \\
\hline Stable in work & 160 & 17 & 16 \\
PT only & 24 & 3 & 3 \\
FT only & 39 & 4 & 3 \\
PT to FT & 38 & 4 & 4 \\
Mix & 59 & 6 & 6 \\
& & & \\
Work enter & 347 & 37 & 37 \\
PT only & 121 & 13 & 14 \\
FT only & 60 & 6 & 6 \\
PT to FT & 71 & 8 & 8 \\
Mix & 95 & 10 & 10 \\
& & & \\
Work in out & 295 & 32 & 34 \\
PT only & 98 & 11 & 11 \\
FT only & 45 & 5 & 6 \\
Both & 152 & 16 & 17 \\
& & & \\
Stable out of work & 113 & 12 & 11 \\
Work exit & 14 & 2 & 2 \\
& & & 100 \\
Total & 929 & 100 & \\
\hline
\end{tabular}

Source: Author's calculations from BHPS

Note: Longitudinal respondent weights were applied for the figures in the final column.

Because of this instability within some of the apparently stable categories, Table 4 groups the trajectories in a different way, separating what I have termed "classic" and "unstable" trajectories. Classic trajectories include those who stay at home along with all those who follow what might be termed uni-directional trajectories (moving into part-time work or full-time work and staying there, or moving through part-time into full-time work). The unstable trajectories are those where women move in the opposite direction at any point. The idea is that uni-directional trajectories are conventionally seen as the norm, and form the base assumption for a policy approach which focuses more on movement into work than on subsequent sustainability. The implicit understanding is that the significant step is this first move, and that this places women on the path to positive employment outcomes. The split between classic and unstable trajectories gives us a sense of how far this assumption is backed up by the 
evidence. In practice, half of the sample turn out to be following an unstable trajectory.

Table 4: Classic and unstable trajectories

\begin{tabular}{lrrr}
\hline & $\begin{array}{c}\text { Number } \\
\text { (unweighted) }\end{array}$ & $\begin{array}{c}\text { Percentage } \\
\text { (unweighted) }\end{array}$ & $\begin{array}{c}\text { Percentage } \\
\text { (weighted) }\end{array}$ \\
\hline Classic trajectories & $\mathbf{4 6 6}$ & $\mathbf{5 0 . 2}$ & $\mathbf{4 8 . 8}$ \\
At home throughout & 113 & 12.2 & 11.5 \\
Stable PT & 24 & 2.6 & 2.6 \\
Stable FT & 39 & 4.2 & 3.5 \\
Stable PT then FT & 38 & 4.1 & 4.2 \\
Moves into work PT, stays there & 121 & 13.0 & 13.8 \\
Moves into work FT, stays there & 60 & 6.5 & 5.7 \\
Moves into PT then FT, stays there & 71 & 7.6 & 7.5 \\
& & & \\
Unstable trajectories & $\mathbf{4 6 3}$ & $\mathbf{4 9 . 9}$ & $\mathbf{5 1 . 3}$ \\
Stable but mix PT and FT & 59 & 6.3 & 5.9 \\
Work enter but mix PT and FT & 95 & 10.3 & 9.8 \\
Work in and out & 295 & 31.8 & 33.7 \\
Work exit & 14 & 1.5 & 1.9 \\
\hline
\end{tabular}

Source: Author's calculations from BHPS

Note: Longitudinal respondent weights were applied for the figures in the final column. Numbers may sum to more than 100 because of rounding.

How does this pattern vary by different groups of women? Among those who were lone parents in the interview following their youngest child's first birthday, instability is more prevalent $-70 \%$ will follow unstable trajectories over the decade, compared to $51 \%$ overall. But numbers are very low - a total of just 55 women in our sample are lone parents at this point, preventing much further analysis in this direction (e.g. a more detailed breakdown of trajectories, or a consideration of the impact of repartnering).

It is possible to say more about differences in trajectories by qualification level. Interestingly, if we split mothers into "low-skilled" (maximum O level at the time of birth) and "high-skilled" (A level, vocational or higher education) we find very similar numbers following the two broad trajectory types. Among the low-skilled group, 51\% follow classic trajectories, compared to $47 \%$ of the high-skilled. This disguises considerable differences in the particular pathways followed, as illustrated in Figure 3. Within the classic group, mothers with more qualifications are much more likely to be in employment, including full-time employment, and much less likely to remain at home throughout. Among the unstable group, mothers with more qualifications are more likely to be unstable but within a working pathway (mixing part-time and full- 
time work). However, perhaps surprisingly, a very similar share of high-skilled and low-skilled mothers - around one-third in each case - are found to be moving in and out of work altogether.

Figure 3: Employment trajectories by qualification level.

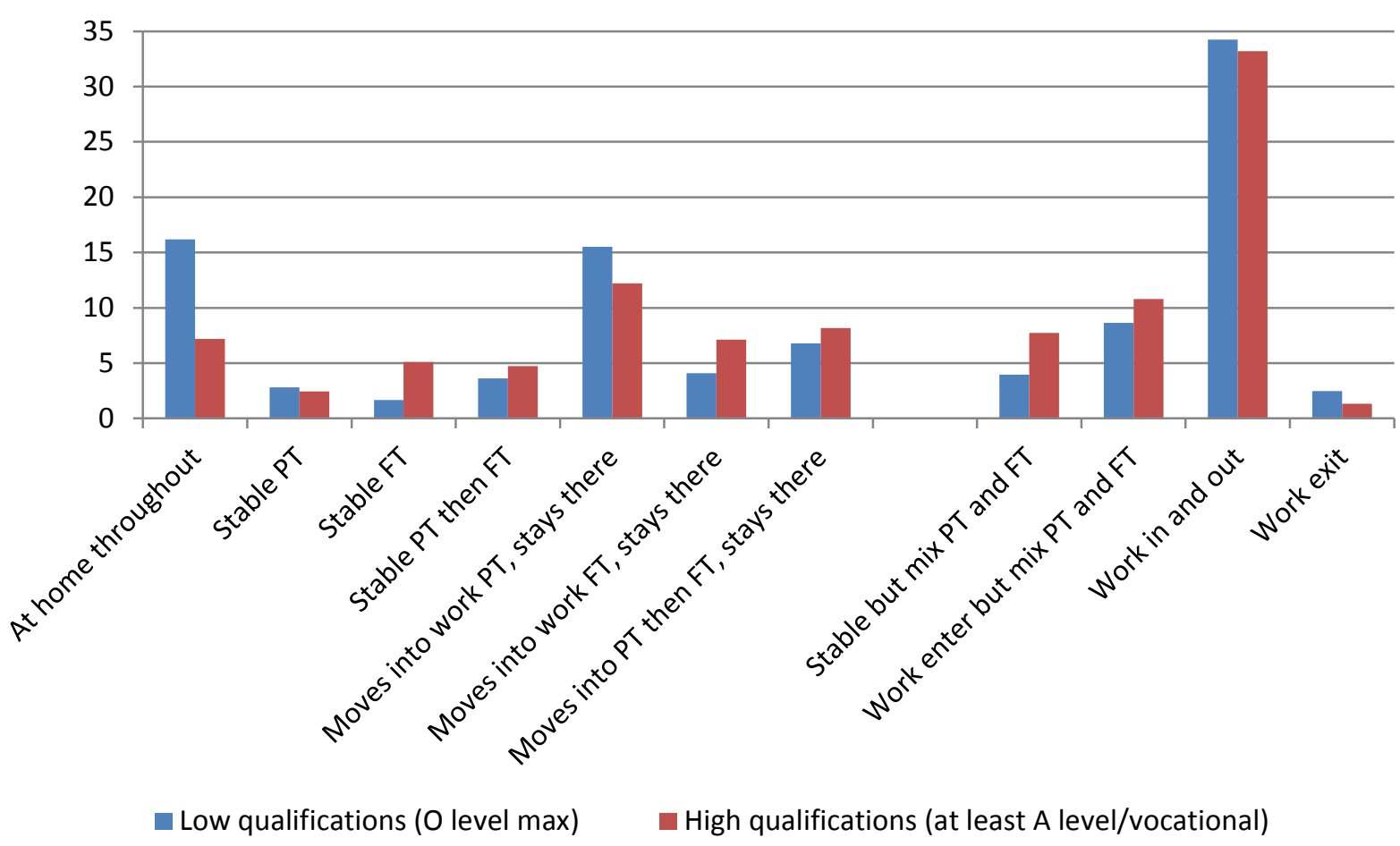

Notes: $\mathrm{N}=920$. Qualification level is measured as soon after birth as data allow. Data are weighted using longitudinal weights.

To sum up, we find mothers in our sample following a variety of employment pathways. One in three are observed moving in and out of work over the decade after the birth of their youngest child, and this is true of both lower-skilled and higherskilled mothers. An additional $16 \%$ stay in employment after entering, but move between full-time and part-time work. The fact that unconventional pathways like these are so common suggests that a heavy focus on the initial move into a job is misplaced and indicates the need for much more consideration of how to make work sustainable. It also suggests that we are likely to see instability in wage and occupational progression. In the next section we go on to explore how far these different employment trajectories are associated with employment outcomes when the youngest child is ten.

\section{Employment history and employment outcomes}

\section{Raw associations}

An examination of employment outcomes at age ten shows big differences between those who were in work when their children were under five and those who were not. 
Table 5 shows a series of labour market outcomes at ten split by labour market status at three. Those who were in work when their youngest was three are much more likely to be working when the child reaches 10, and (among those working) are more likely to have higher hourly pay, to be a manager or supervisor and to have higher occupational class as measured using the National Statistics Socio-Economic Classification (NS-SEC). The only labour market outcome showing no significant difference at ten by employment status at three is job satisfaction.

Table 5: Employment outcomes when youngest child is ten, by employment status when youngest was three and by education

\begin{tabular}{|l|c|c|c|c|c|c|}
\hline & \multicolumn{2}{|c|}{ All respondents } & \multicolumn{2}{c|}{ Maximum O levels } & \multicolumn{2}{c|}{$\begin{array}{c}\text { levels, vocational } \\
\text { or more }\end{array}$} \\
\hline & $\begin{array}{c}\text { In work } \\
\text { at 3 }\end{array}$ & $\begin{array}{c}\text { At home } \\
\text { at 3 }\end{array}$ & $\begin{array}{c}\text { In work } \\
\text { at 3 }\end{array}$ & $\begin{array}{c}\text { At home } \\
\text { at 3 }\end{array}$ & $\begin{array}{c}\text { In work } \\
\text { at 3 }\end{array}$ & $\begin{array}{c}\text { At home } \\
\text { at 3 }\end{array}$ \\
\hline In paid work at 10 (\%) & $\mathbf{8 7}$ & $\mathbf{5 8}$ & $\mathbf{8 6}$ & $\mathbf{5 0}$ & $\mathbf{8 8}$ & $\mathbf{6 8}$ \\
\hline $\begin{array}{l}\text { Median hourly pay (£, } \\
\text { 2007 prices) }\end{array}$ & $\mathbf{8 . 6 2}$ & $\mathbf{6 . 8 1}$ & $\mathbf{7 . 2 9}$ & $\mathbf{6 . 3 4}$ & $\mathbf{9 . 6 2}$ & $\mathbf{7 . 1 4}$ \\
\hline $\begin{array}{l}\text { Manager or supervisor } \\
\text { (\% of those in work) }\end{array}$ & $\mathbf{3 0}$ & $\mathbf{2 0}$ & $\mathbf{2 6}$ & $\mathbf{1 1}$ & 31 & 29 \\
\hline $\begin{array}{l}\text { Managerial and } \\
\text { professional class } \\
\text { (\% of those in work) }\end{array}$ & $\mathbf{3 8}$ & $\mathbf{2 6}$ & $\mathbf{2 1}$ & $\mathbf{1 0}$ & 50 & 41 \\
\hline $\begin{array}{l}\text { Job satisfaction } \\
\text { (median score; range } \\
\text { from 1-7) }\end{array}$ & 5.5 & 5.8 & 5.7 & 5.7 & 5.4 & 5.8 \\
\hline
\end{tabular}

Note: All figures were calculated using longitudinal weights. T-tests were run using non-weighted data and all differences in bold were found to be significant at the $99 \%$ confidence level. For hourly pay the test was run on mean rather than median pay. "Managerial and professional class" refers to the top two categories of the National Statistics Socio-Economic Classification.

Of course this is of little surprise and is just a starting point: those who go back into work early are likely to be those with qualifications as well as a commitment to the labour market. The interesting question is how far this reflects choices made after children were born, rather than other underlying characteristics. A crude second step is to examine these differences for those with low or no qualifications separately from those with higher qualifications. These results are also presented in Table 5, and in Figure 4 which shows the ratio between those at home and at work for all women and for the two skill groups separately. Interestingly, for several of the indicators we see bigger differences for the group of low-skilled mothers 
Figure 4: Differences in maternal employment outcomes when youngest child is ten by employment status seven years earlier.

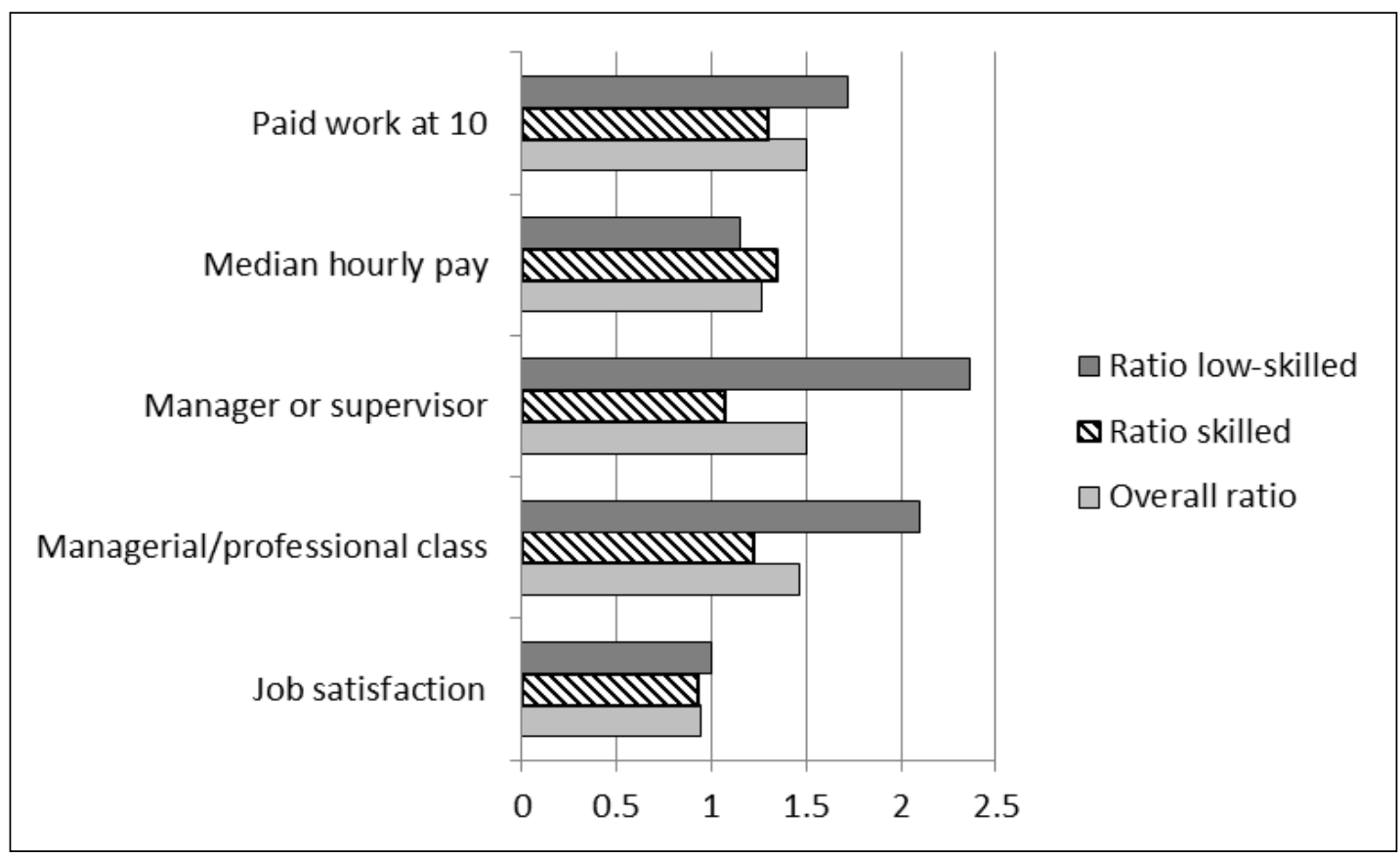

Note: These ratios show the extent of the difference in employment outcomes at ten between mothers at home and at work when their youngest child was three. For instance, we can see that among lowskilled mothers, those in work when their youngest was three years old were more than twice as likely to be managers or supervisors seven years later.

Still, much of this is likely to be endogenous. Mothers who return to work when their children are young are likely to differ from mothers who stay at home in what Anderson et al. (2003) (p.279) calls "unobservable, wage-enhancing capital"; in particular, they are probably more committed to their careers. The employment they go into may also be different: they may be returning to a job where they have already established firm-specific skills which are not reflected in broad qualification levels.

How do we net out these factors in order to assess the impact of the decisions themselves? One option would be to examine changes in wages or occupational status over time, but this is difficult here because of the nature of the dataset. We rely on the BHPS employment histories to build a sample large enough for analysis, and this means we do not have good data on pay in previous jobs. Other datasets are better for this purpose, and in related work we look at growth in wages using the British Lone Parent Cohort and the Families and Children Study (see Stewart, 2009; Bastagli and Stewart (2011)). Here, we simply try to control for all the measurable factors likely to drive both the pathway and the later outcomes, to see whether we can identify an independent impact of the pathway. However, we must accept that our estimated coefficients will be biased upwards if there are unobserved confounding variables not captured by our controls. 


\section{Employment status}

We examine four employment outcomes at the point at which the youngest child is ten: whether or not a mother is in paid work; the hourly wage; job satisfaction; and occupational classification. The first three outcomes are analysed using regression techniques (see below for discussion of occupational classification). In the regressions, our aim is to control for all factors which are likely to drive both the employment trajectory and the outcome, to identify whether an association between the two remains which is not explained by these other factors. Thus all the regressions control for educational qualifications at birth, years of work experience prior to the birth, potential work experience (age), the number of children, and whether or not the household were owner-occupiers at birth. ${ }^{3}$ This last is intended to capture otherwise unobserved work commitment: those who have bought their own home may act differently as a result of the pressure of a mortgage, while the act of buying a property (and the fact that a bank was willing to put up the money) is also likely to be a reflection of pre-existing motivation. We also include a set of dummies for the year of birth of the youngest child to control for the fact that mothers are facing different employment conditions than each other when their children are the same age. We also considered including lone parent status close to the time of birth, but decided that this variable was most likely to influence later employment outcomes via its effect on employment trajectory rather than having an independent additional effect. (In practice, this variable was in any case insignificant in all models except some job satisfaction models.)

Table 6 shows predicted probabilities for employment status at ten, the results of logit regression. Predicted probabilities are presented for women with a number of alternative characteristics, dependent on the point at which they were first observed in work after the birth (regardless of the later trajectory). The characteristics which vary are educational background and housing tenure around the time of birth; these are the variables which showed up as significantly associated with employment status at ten. Other variables are set as constant across all the groups: women are assumed to have two children, be of average age and have average levels of work experience prior to birth.

It is clear, first, that within each educational and tenure group the likelihood of employment at ten is greater for those who returned to work earlier. However, the differences between those observed entering work before three and those observed between three and five are generally not very large (in fact in all cases the $95 \%$ confidence intervals overlap for these categories). afterwards; if earlier we measure these at the time of the first BHPS interview in 1991. 
Table 6: Predicted probabilities for being in work when youngest child is ten

\begin{tabular}{llcc}
\hline $\begin{array}{l}\text { Top qualification } \\
\text { (at birth) }\end{array}$ & $\begin{array}{l}\text { First observation } \\
\text { in work }\end{array}$ & $\begin{array}{c}\text { Housing tenure: } \\
\text { private or social } \\
\text { renting }\end{array}$ & $\begin{array}{c}\text { Housing tenure: } \\
\text { owner-occupier }\end{array}$ \\
\hline No qualifications & Before age 3 & 0.82 & 0.92 \\
& Between 3 and 5 & 0.67 & 0.83 \\
Not before 6 & 0.25 & 0.45 \\
Oefore age 3 & Between 3 and 5 & 0.85 & 0.93 \\
Advanced or & Not before 6 & 0.29 & 0.86 \\
vocational & Between 3 and 5 & 0.87 & 0.50 \\
qualifications & Not before 6 & 0.75 & 0.94 \\
Degree & Before age 3 & 0.33 & 0.88 \\
& Between 3 and 5 & 0.91 & 0.55 \\
& Not before 6 & 0.82 & 0.96 \\
\hline
\end{tabular}

Notes: Binary logit regression. $\mathrm{N}=911$. R squared=0.24. Year dummies included. All women are assumed to have two children, be of average age and have average levels of work experience prior to the birth. "First observation in work" refers to just that, regardless of the later trajectory; that is, those who will subsequently leave employment again are also included.

Second, the point of return is more strongly associated with later outcome for those with lower levels of qualifications and for those who do not own their homes. Among mothers who both have a degree and are owner-occupiers there is a negligible difference between the "before three" group (96\% in employment at ten) and the "35 " group (92\%). Even among those still not observed in work by the sixth birthday, $65 \%$ of mothers in this category will be working at the interview after the child turns ten. In contrast, for mothers with no qualifications and living in social housing or renting privately, being observed in work before three increases the probability of working at ten more than three-fold compared to a mother not observed working in the first five years (a probability of $82 \%$ compared to $25 \%$ ). Note that mothers with a degree but living in rented accommodation look almost identical in their probability of working to mothers with no qualifications but living in owner-occupied housing.

What can we take from these results? One interpretation is that encouraging mothers into work relatively quickly after the birth of a child really is a sensible way to increase their probability of employment later on, and that this is particularly important for mothers with lower or no qualifications, and for those who live in rented housing. A second interpretation is that within each qualification and tenure group the 
mothers who returned earlier are simply different from those who did not in ways that we still have not managed to control for, and that these results offer no more than a description of the underlying work motivation of women in different categories. The owner-occupier variable appears to be capturing some of these differences in motivation, but it is unlikely that it is successfully picking up all of it.

The most plausible (if rather unsatisfactory) answer is that the truth lies somewhere in the middle. Differences in probabilities will to some extent reflect differences between women, so we would be naïve to assume that a mother's probability of employment at ten would be increased as much as three-fold if she had only entered employment earlier. But at the same time the scale of these differences are unlikely to be explained entirely by differences in hidden characteristics. It is clearly likely that the act of working would increase the future likelihood of employment through familiarity, expanded networks and contacts and exposure to other work-orientated peers. If maternal employment as a child approaches secondary school age is itself an important policy goal, encouraging and facilitating employment in the earlier years may then be sensible, with particular reason to focus on women with few qualifications and on women living in rented housing. In the following sub-sections we go on to look at the quality of work in these jobs at ten - how well they are paid, their job satisfaction and occupational status - and whether these indicators are associated with earlier pathways.

\section{Wages}

Table 7 shows the results of OLS regressions run to estimate the association between employment pathway after the birth and hourly wages a decade on. In these regressions dummy variables were included to capture three 'classic' and one unstable pathway - returning to work by the interview before the child's third birthday and being observed consistently in work thereafter (the control group); returning after the third but before the sixth birthday; returning after the sixth birthday; and moving in and out of work over the decade. Regressions were run on the sample as a whole and then separately for women with higher qualifications (at least advanced or vocational) and those with lower qualifications (maximum $\mathrm{O}$ level equivalent).

Because the regressions are run on the log of hourly wages, the coefficients can be simply interpreted in percentage terms. Thus entering stable work between three and five is associated with an hourly wage $21 \%$ lower than entering before three, while entering after five is associated with a reduction of $27 \%$. Moving in and out of employment over the decade appears to carry a similar penalty of $26 \%$. Note that these coefficients are relatively small in comparison to the benefits associated with higher education (wages 63\% higher) but are considerably larger than those associated with advanced or vocational qualifications (13\%). They are also larger than the 17\% penalty for part-time working. 
Table 7: Regression results for log hourly wages when youngest child is ten (OLS)

\begin{tabular}{lccc}
\hline & $\begin{array}{c}\text { All } \\
\text { observations }\end{array}$ & $\begin{array}{c}\text { High skilled } \\
\text { only }\end{array}$ & $\begin{array}{c}\text { Low skilled } \\
\text { only }\end{array}$ \\
\hline Trajectory groups (control: enters work before the child is 3 and stays there*) & \\
Enters work 3 to 5 and stays there* & $\mathbf{- 0 . 2 1}$ & $\mathbf{- 0 . 2 5}$ & $\mathbf{- 0 . 1 3}$ \\
Enters work after 5 and stays there* & $(-4.22)$ & $(-3.29)$ & $(-2.13)$ \\
& $\mathbf{- 0 . 2 7}$ & $\mathbf{- 0 . 3 2}$ & $\mathbf{- 0 . 2 1}$ \\
Moves in and out of work & $(-4.54)$ & $(-3.47)$ & $(-3.36)$ \\
& $-\mathbf{- 0 . 2 6}$ & $\mathbf{- 0 . 3 3}$ & $\mathbf{- 0 . 1 4}$ \\
\hline
\end{tabular}

\section{Control variables}

Maximum education at child's birth

(control=no qualifications except middle column where control is Advanced/vocational)

\begin{tabular}{lccc} 
Higher Education & $\mathbf{0 . 6 3}$ & $\mathbf{0 . 5 0}$ & -- \\
Advanced/ vocational qualifications & $(9.89)$ & $(8.03)$ & -- \\
O level equivalent & $\mathbf{0 . 1 3}$ & -- & \\
& $(3.06)$ & & 0.05 \\
Owner-occupier at birth & 0.04 & -- & $(1.05)$ \\
& $(0.89)$ & & $\mathbf{0 . 0 8}$ \\
Part-time at 10 & 0.02 & -0.04 & $(1.68)$ \\
Number of children & $(0.58)$ & $(-0.55)$ & $\mathbf{- 0 . 1 6}$ \\
& $\mathbf{- 0 . 1 7}$ & $\mathbf{- 0 . 1 8}$ & $(-3.37)$ \\
Age & $(-5.00)$ & $(-3.61)$ & -0.02 \\
Age squared & 0.02 & $\mathbf{0 . 0 7}$ & $(-0.78)$ \\
Years of work experience prior to birth & $(0.58)$ & $(1.68)$ & $\mathbf{0 . 1 2}$ \\
& 0.04 & 0.002 & $(1.67)$ \\
Years of prior work experience squared & $(0.76)$ & $(0.02)$ & $\mathbf{- 0 . 0 0 1}$ \\
Year dummies & -0.0004 & 0.0002 & $(-1.65)$ \\
\hline R squared & $(-0.55)$ & $(0.18)$ & 0.02 \\
N & 0.008 & 0.003 & $(1.23)$ \\
\hline
\end{tabular}

Notes: Results of OLS regressions run with robust standard errors. Bold type indicates significance at the $1 \%$ level; bold and italics indicates significance at $5 \%$ level. Tstatistics are given in brackets. * 'Stays there' means is observed in work in every annual snapshot thereafter. 
The next question is whether this holds true for everyone, whatever their qualification levels. In fact, as the second and third columns of Table 7 show, while all the trajectories are significantly associated with wages at ten for both higher and lower skilled women, the coefficients are much larger for the higher skilled. For those with at least advanced or vocational qualifications, entering work between three and five is associated with a $25 \%$ reduction in the hourly wage at ten compared to those with a steady employment record; for those with maximum $\mathrm{O}$ levels the equivalent penalty is $13 \%$. Similarly, those entering after five have wages which are $32 \%$ lower for the more highly qualified group and $21 \%$ lower for the less qualified. The biggest difference is for those who move in and out of work over the decade; $33 \%$ lower for the skilled group and just $14 \%$ lower for those with O levels or no qualifications.

One possible explanation for the lower penalty associated with an unstable pathway or later return for the less qualified is that the introduction of the National Minimum Wage in 1999 placed a floor on wages at the bottom of the distribution. If all jobs pay at least the NMW, and if employers make up for the cost of the NMW in part by flattening wage-growth profiles for low-paid workers, the penalty for reduced experience or an unstable work record will be limited: a worker can leave the labour market confident that the job they return to will pay at least the minimum wage. To investigate this we run regressions separately for mothers whose youngest child reaches ten before 1999, and those whose work history includes at least one year post1999 (the youngest child reaches ten in 2000 or later). If the NMW is having the anticipated effect, we would expect penalties for time out of work to be smaller in the later than the earlier period for the low-skilled group, while the difference in penalty between high- and low-skilled women should be more marked in the later period. As Table 8 shows, neither pattern emerges clearly from the data. The analysis is somewhat compromised by small sample size, but it is clear that the penalties associated with time out of work were larger for more highly skilled than for lower skilled women even prior to the introduction of the NMW. 
Table 8 Trajectory coefficients for pre-NMW and post-NMW samples.

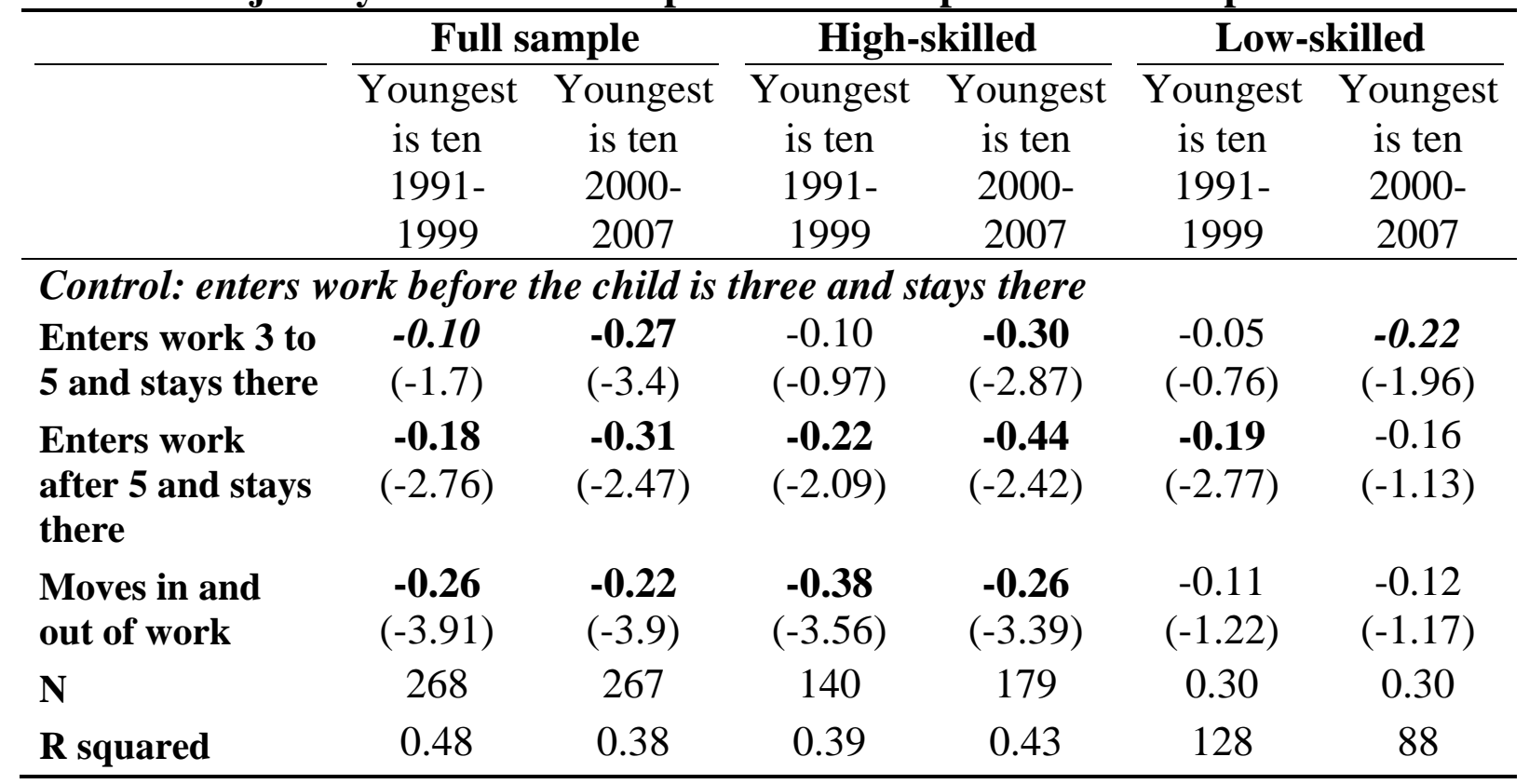

Notes: Results of OLS regressions run with robust standard errors. The same control variables as in Table 7 were included. Bold type indicates significance at the $1 \%$ level; bold and italics indicates significance at $5 \%$ level. T-statistics are given in brackets.

\section{Job Satisfaction}

Our third employment outcome, job satisfaction, was the only outcome to show no significant differences by earlier employment status in the raw associations presented in Table 5. It is perhaps of no surprise then that none of our trajectories turn out to be significant in the regression analysis. Job satisfaction does not appear to be explained by length of time or stability in work, or indeed by qualification levels. In fact, just two of the variables in the job satisfaction model were significant (both at the $5 \%$ but not the $1 \%$ level): higher skilled mothers were found to have somewhat higher job satisfaction if they worked part-time, and lower-skilled mothers had lower job satisfaction if they were lone parents.

\section{Socio-economic classification}

The final employment outcome we have available is socio-economic occupational classification (NS-SEC). We are interested in whether a stable employment history enables women to climb up the occupational scale, moving (for example) from routine to semi-routine occupations, or from semi-routine jobs to jobs with managerial responsibilities. Does a steady position on the supermarket checkout lead on to a supervisory role? However, here problems of endogeneity become particularly acute. Managerial and professional positions are likely to offer much greater stability than lower-skilled occupations, so trying to predict NS-SEC status at ten on the basis of employment pathway during the previous decade seems ill-advised - more so than predicting wage levels or job satisfaction because this indicator is blunter (showing less variation) and because it is more static over time.

We do however have the advantage of knowing women's occupational status in each year they are employed (although there are missing observations), not just in the years 
they are employed after 1991 (as is the case for wage and job satisfaction). Hence we take a slightly different approach here, and examine movement in NS-SEC occupational status over time. Table 9 presents results for movement in occupational status for two groups of women - those observed in work at the observation after the child's third birthday and at every observation thereafter, and those seen moving in and out of work over time.

Table 9 Occupational status and occupational progression for two groups of women

\begin{tabular}{|c|c|c|c|c|c|c|}
\hline & \multicolumn{2}{|c|}{$\begin{array}{c}\text { Occupational } \\
\text { status Year 3/first } \\
\text { observation in } \\
\text { work }(\%) \\
\end{array}$} & \multicolumn{2}{|c|}{$\begin{array}{c}\text { Observed moving } \\
\text { up over decade } \\
(\%)\end{array}$} & \multicolumn{2}{|c|}{$\begin{array}{c}\text { Observed moving } \\
\text { down over decade } \\
(\%)\end{array}$} \\
\hline & $\begin{array}{c}\text { Stable } \\
\text { work }\end{array}$ & $\begin{array}{l}\text { In and } \\
\text { Out }\end{array}$ & $\begin{array}{l}\text { Stable } \\
\text { work }\end{array}$ & $\begin{array}{c}\text { In and } \\
\text { Out }\end{array}$ & $\begin{array}{l}\text { Stable } \\
\text { work }\end{array}$ & $\begin{array}{c}\text { In and } \\
\text { Out }\end{array}$ \\
\hline $\begin{array}{l}\text { Higher } \\
\text { managerial/ } \\
\text { professional }\end{array}$ & 3 & 0 & -- & -- & 30 & 100 \\
\hline $\begin{array}{l}\text { Lower managerial/ } \\
\text { professional }\end{array}$ & 27 & 14 & 10 & 5 & 14 & 36 \\
\hline Intermediate & 23 & 20 & 44 & 30 & 9 & 43 \\
\hline $\begin{array}{l}\text { Small emplyrs and } \\
\text { own account wrkrs }\end{array}$ & 8 & 10 & 46 & 38 & 8 & 15 \\
\hline $\begin{array}{l}\text { Lower supervisory } \\
\text { and technical }\end{array}$ & 7 & 5 & 30 & 8 & 30 & 77 \\
\hline Semi-routine & 17 & 24 & 40 & 50 & 8 & 17 \\
\hline Routine & 14 & 27 & 66 & 62 & -- & -- \\
\hline Total (\%) & 100 & 100 & 35 & 40 & 11 & 23 \\
\hline $\mathbf{N}$ & 288 & 270 & 101 & 107 & 32 & 63 \\
\hline
\end{tabular}

Notes: 'Stable work' group are those observed in work when the child is three and in every observation thereafter. 'In and out' are those who move in and out of work over the decade. For the first group occupational status is measured when the child is three and when the child is ten; for the second group the first and last possible observations are used for each individual.

The first two columns show that, as expected, starting points are rather different, with much greater likelihood of starting in higher status occupations for those who will remain in stable work. What we are interested in is the likelihood of progression over the decade. For the stable group, the third column indicates good rates of upward mobility, while the fifth column shows much more limited likelihood of moving downward: for example, $46 \%$ of those starting in an intermediate profession moved up to a managerial or professional position over the period, compared to $9 \%$ who moved down to a lower classified job. For the women following a less stable pathway, the likelihood of upward movement out of most employment categories looks almost as 
high, with strong rates of upward mobility out of routine and semi-routine jobs in particular: half of those starting in a semi-routine job will progress to a job with a higher classification. Overall, $40 \%$ of the in-and-out group move up over time, compared to $35 \%$ of the stable group, although this partly reflects the lower starting point, with more headroom to grow into.

However (and despite the lower starting point), downward mobility is also much more likely for the in-and-out group than for the stable workers. Rates of downward movement are markedly higher in all categories, and affect $23 \%$ of the in-and-out workers overall, compared to just $11 \%$ of those in stable employment.

\section{Conclusions}

The analysis presented in this paper used data from Britain's longest running household panel survey to explore whether moving into work soon after the birth of a child has a measurable impact on later employment outcomes, for women with few qualifications as well as for those with advanced or higher education. It asked two sub-questions. First, do mothers on the whole remain in employment once they have taken a job? And do wages and other employment outcomes further down the line reflect the pathway taken? For simplicity, the analysis concentrated on pathways and outcomes after the birth of the youngest child.

With respect to the first question, we found that most mothers do not follow a smooth one-way movement into work. Employment trajectories are volatile, and this is true for mothers with qualifications as well as for those without. Overall, half of the sample were found to be following what we termed an "unstable" trajectory, including one in three observed moving in and out of work over the decade. These figures were very similar for both higher-skilled and lower-skilled mothers, with 33-34\% in the inand-out category in each case. Because the analysis is based on annual snapshots rather than continuous employment histories, the figures are likely to be conservative estimates.

What of the impact on employment outcomes when the youngest child is ten? Despite employment instability, it is clear that mothers who return to work sooner after the child's birth are much more likely to be observed in work when the child is ten, even after including all available control variables. This is true across skill levels, but an earlier return appears most important in predicting later employment for mothers who are more disadvantaged - those who have few or no qualifications and do not own their own homes.

When we examine wages, the story is rather different. Here, more time at home or a broken trajectory has the largest impact on more highly qualified women. Among women with at least advanced or vocational qualifications, wages when the youngest child is ten are $32 \%$ lower for those who returned to stable employment after the child turned five than for those who returned before the child's third birthday, and 33\% 
lower for those observed moving in and out of work over the period. ('Stable' work means that we observed the mother in employment in each annual snapshot after the initial return.) For the lower skilled group, apparent wage penalties were also identified but they were substantially smaller, as human capital theory would predict: a $21 \%$ penalty for returning after five compared to before three, and a $14 \%$ penalty for moving in and out of work. Note that these estimates should be seen as upper bounds, both because the coefficients are almost certainly biased upwards by unobserved confounding variables (such as passion for one's job), and because of an endogeneity problem: women are more likely to remain in jobs which offer good prospects, so to some extent the wage trajectory will drive the employment pathway, as well as vice versa.

Because the endogeneity problem seems particularly acute with regard to occupational status, this part of the analysis stuck to a descriptive approach, simply tracking upward and downward occupational mobility over the decade for those observed consistently in employment from three to ten and for those seen moving in and out of work. Upward mobility was found to be reassuringly common for both groups, with $35 \%$ of stable workers and $40 \%$ of the in-and-out group moving to a higher status job over the period. But downward mobility was much more prevalent among those moving in and out of work $-23 \%$ moved down in status, compared to $11 \%$ of the stable workers.

Finally, the fourth employment outcome we looked at, job satisfaction when the youngest child is ten, showed no association with employment pathway for women in either skill category.

What do we take away from this analysis? First, the fact that results differ substantially for women with different qualification levels confirms the importance of differentiated analysis; the average effects identified in much of the existing analysis of gender and family gaps disguise important heterogeneity.

Second, the typology of employment pathways presents a challenge to conventional wisdom about common employment trajectories after birth. If unstable pathways are the norm, even after the birth of a youngest child, this points to the need for much more focus on employment sustainability as well as on initial entry. The dominance of unstable pathways also carries implications for related policies which are based on the assumption that stable employment is standard. The childcare tax credit, for example, is payable only where all resident parents work, so a mother moving out of a job is likely to have to disrupt her child's care arrangements. In a world in which movement in and out of work is the norm (and given what we know about the importance of continuity of care for children) a subsidy paid directly to the provider or a demandside payment which included non-working parents would be a better design.

Third, there is some evidence here that early employment may have long-term payoffs, even for women with few qualifications. Working in the pre-school years seems to have the greatest impact on the likelihood of employment at ten for the more disadvantaged, and wages are higher at ten for those who have been in stable work for 
longer. In both cases, however, some of the association will reflect unobservable selection effects. The levels of occupational progression, as indicated by NS-SEC status, are encouraging, although greater investigation of the sorts of job transitions that are being made would be interesting. On the other hand, the wage returns are fairly small in size for those with low qualifications, especially given that the estimates must be seen as an upper bound. It would be unlikely that the mothers who did not return to work early could have achieved the results of others with the same observed characteristics who did, had they only done so.

Of course there are many other reasons to encourage maternal employment besides potential medium- and long-term employment outcomes: immediate income gains, possible benefits of formal childcare, the provision of a working role-model for children, and some evidence that employment may reduce maternal depression, especially for lone parents who prefer to work (see discussion in Millar (2008)). If there are in addition any medium-term employment and wage gains they may perhaps be seen as a bonus. However, given the explicit policy focus on work as a route to better outcomes the relatively small size of the gains (alongside the instability of mothers' employment) may also be seen as disappointing. The results appear to underline the need for social policies which foster sustainability and progression in employment in addition to those which facilitate the initial move into a job. 


\section{References}

Amuedo-Dorantes, C. and J. Kimmel (2005) "The Motherhood Wage Gap for Women in the United States: The Importance of College and Fertility Delay." Review of Economics of the Household 3: 17-48.

Anderson, D. J., M. Binder and K. Krause (2003) "The Motherhood Wage Penalty Revisited: Experience, Heterogeneity, Work Effort and Work-Schedule Flexibility." Industrial and Labor Relations Review 56(2): 273-294.

Bastagli, F. and K. Stewart (2011, forthcoming) "A route out of poverty? Mothers' employment and wages in the Families and Children Study". London, Centre for Analysis of Social Exclusion, LSE.

Brooks-Gunn, J., W. Han and J. Waldfogel (2010) "First Year Maternal Employment and Child Development in the First Seven Years." Monographs of the Society for Research in Child Development 75.

Budig, M. and P. England (2001) "The wage penalty for motherhood." American Sociological Review 66(2): 204-225.

Burtless, G. (1995) "Employment Prospects of Welfare Recipients". The Work Alternative: Welfare Reform and the Realities of the Job Market. D. S. Nightingale and R. H. Haveman. Washington D.C., Urban Institute Press.

Card, D. and J. E. DiNardo (2002) "Skill-Biased Technological Change and Rising Wage Inequality: Some Problems and Puzzles." Journal of Labor Economics 20(4): 733-83.

Card, D. E., Michalopoulos and P. K. Robins (1999) "Measuring Wage Growth Among Former Welfare Recipients". Working Paper Series. Berkeley, CA, University of California.

Connolly, H. and P. Gottschalk (2006) "Differences in Wage Growth by Education Level: Do Less Educated Workers Gain Less from Work Experience". Boston, Mass, Boston College Economics Department.

Connolly, H., P. Gottschalk and K. Newman (2003) "Wage Trajectories of Workers in Poor Households: The National Experience". Paper presented by Peter Gottschalk at the CASE Social Exclusion seminar, London School of Economics, May 2004.

Datta Gupta, N. and N. Smith (2002) "Children and Career Interruptions: The Family Gap in Denmark." Economica 69(November): 609-629.

Dustmann, C. and C. Meghir (2005) "Wages, Experience and Seniority." Review of Economic Studies 72(1): 77-108.

Ellwood, D., E. Ty Wilde and L. Batchelder (2009) "The Mommy Track Divides: The Impact of Childbearing on Wages of Women of Differing Skill Levels". New York, Russell Sage Foundation.

Evans, M., S. Harkness and R. Arigoni Ortiz (2004) Lone Parents Cycling Between Benefits and Work. London, Department for Work and Pensions. 
Gladden, T. and C. Taber (2000) "Wage Progression Among Less Skilled Workers". Finding Jobs: Work and Welfare Reform, D. E. Card and R. M. Blank. New York, Russell Sage Foundation: 160-192.

Gregg, P., H. S and S. S (2009) "Welfare Reform and Lone Parents in the UK." Economic Journal 119(535): F38-F65.

Gregg, P., E. Washbrook, C. Propper and S. Burgess (2005) "The effects of a mother's return to work decision on child development in the UK." Economic Journal 115(48-80).

Hansen, K. and D. Hawkes (2009) "Early Childcare and Child Development." Journal of Social Policy 38(2): 211-239.

Harkness, S. (2006) "Lone parents cycling in and out of benefits". Staying On, Stepping Up:How Can Employment Retention and Advancement Policies Be Made to Work for Lone Parents? K. Bell. London, One Parent Families.

Harkness, S. and J. Waldfogel (2003) "The family gap in pay: Evidence from seven industrialized countries." Research in Labor Economics 22: 369-413.

Heckman, J. J., L. Lochner and C. Taber (1998) "Explaining Rising Wage Inequality: Explorations with a Dynamic General Equilibrium Model of Labor Earnings with Heterogeneous Agents." Review of Economic Dynamics 1(1): 1-58.

HM Treasury (1999) Tackling Poverty and Extending Opportunity. London, HM Treasury.

Jacobsen, J. and L. Levin (1995) "The Effects of Intermittent Labor Force Attachment on Women's Earnings.” Monthly Labor Review 118(September): 14-19.

Joshi, H., P. Paci and J. Waldfogel (1998) "The wages of motherhood: better or worse?" Cambridge Journal of Economics 23(5): 543-64.

Lemieux, T. (2003) “The 'Mincer Equation' Thirty Years After: Schooling, Experience and Earnings". Jacob Mincer: A Pioneer of Modern Labor Economics. S. Grossbard. New York, Springer.

McKnight, A. (2000) Trends in Earnings Inequality and Earnings Mobility 19771997. Warwick, Institute for Employment Research.

Millar, J. (2008) "Work is good for you: lone mothers, children, work and wellbeing”. Third Annual KELA lecture, The Social Insurance Institution, Helsinki.

Murphy, K. M. and F. Welch (1992) “The Structure of Wages.” The Quarterly Journal of Economics 107(1): 285-326.

Sigle-Rushton, W. and J. Waldfogel (2007) "Motherhood and women's earnings in Anglo-American, Continental European and Nordic countries." Feminist Economics 13(2): 55-91.

Stewart, K. (2009) "Employment and Wage Trajectories for Mothers Entering LowSkilled Work: Evidence from the British Lone Parent Cohort." Social Policy and Administration 43(5): 483-507. 
Stewart, M. B. and J. Swaffield (1998) "The earnings mobility of low-paid workers in Britain". Low Pay and Earnings Mobility in Europe. R. Asplund, P. J. Sloane and I. Theodossiou. Cheltenham, Edward Elgar.

Stewart, M. B. and J. Swaffield (1999) "Low Pay Dynamics and Transition Probabilities." Economica 66(261): 23-42.

Sylva, K., E. Melhuish, P. Sammons, I. Siraj-Blatchford and B. Taggart (2004) The Effective Provision of Pre-School Education (EPPE) Project Technical Paper 12 - The Final Report. London, University of London.

Todd, E. L. (2001) "Educational Attainment and Family Gaps in Women's Wages: Evidence from Five Industrialized Countries". Luxembourg, Luxembourg Income Study

Waldfogel, J. (1995) "The Price of Motherhood: Family Status and Women's Pay in a Young British Cohort." Oxford Economic Papers 47(4): 584-610.

Waldfogel, J. (1997) “The effect of children on women's wages.” American Sociological Review 62(2): 209-217.

Waldfogel, J. (1998) "The Family Gap for Young Women in the United States and Britain: Can Maternity Leave Make a Difference." Journal of Labor Economics 16(3): 505-539. 